\title{
Por que mais médicos no Brasil? Da política à formação.
}

\section{Why else doctors program in Brazil? Policy and formation.}

\section{¿Por qué más médicos en Brasil? Politica y formación.}

\author{
Maria Fátima de SOUSA ${ }^{1}$ \\ Marcos da Silveira FRANCO ${ }^{2}$ \\ Dais Gonçalves ROCHA ${ }^{3}$ \\ Natália Fernandes de ANDRADE ${ }^{4}$ \\ Elizabeth Alves de Jesus PRADO ${ }^{5}$ \\ Ana Valéria M. MENDONÇA ${ }^{6}$
}

RESUMO: A partir de uma revisão e análise documental dos marcos legal e histórico do Sistema Único de Saúde, ao longo das últimas três décadas, são sinalizadas as principais diretrizes para a política de formação e educação permanente em saúde tendo como questão de estudo: Por que mais médicos no Brasil? O diagnóstico situacional da necessidade de médicos no Brasil é analisado em uma perspectiva comparada internacional. Para que o Programa Mais Médicos não seja, meramente, mais um estratégia pontual dentre outras iniciativas governamentais do período analisado, ao final, são apresentados alguns "caminhos" visando favorecer a sustentabilidade desta ação e contribuir para expandir e qualificar a atenção básica no Brasil.

Palavras chave: Sistema Único de Saúde; Atenção Básica à Saúde; Recursos Humanos em Saúde.

ABSTRACT: From a review and documentary analysis of legal and historical landmarks of the Unified Health System over the past three decades, are signaled the main guidelines for the formation of policy and professional health education with as a matter of study: Why else Doctors in Brazil? The situational diagnosis of the need for doctors in Brazil is analyzed in an international comparative perspective. For the More Doctors Program is not merely another point strategy among other government initiatives of the reporting period, at the end, they present some "paths" aimed at promoting the sustainability of this action and contribute to expand and qualify primary care in 1 Doutora em Ciências da Saúde (UnB). Professora do Programa de Pós Graduação em Saúde Coletiva da Faculdade de Ciências da Saúde da Universidade de Brasília (FS/UnB). mariafatimasousa@uol.com.br.

2 Médico Sanitarista. Doutorando em Ciências da Saúde pela Faculdade de Ciências da Saúde da Universidade de Brasília.

3 Professora do Programa de Pós Graduação em Saúde Coletiva da FS/UnB.

4 Bacharel em Saúde Coletiva pela Faculdade de Ceilândia/UnB.

5 Mestranda em Saúde Coletiva pelo Programa de Pós Graduação em Saúde Coletiva da FS/UnB. Bacharel em Saúde Coletiva pela Faculdade de Ceilândia/UnB. Bolsista CNPq-Brasil.

6 Doutora em Ciência da Informação (UnB). Professora do Programa de Pós Graduação em Saúde Coletiva da FS/ UnB. 
Brazil.

Key words: Health Unic System; Primary Health Care; Human Resources for Health.

RESUMEN: A partir de un análisis de revisión y documental de los hitos legales e históricos del Sistema Único de Salud en las últimas tres décadas, se señalizan las principales directrices para la formación de la política y la educación profesional de la salud como una cuestión de estudio: ¿Por qué Más Médicos en Brasil? El diagnóstico situacional de la necesidad de que los médicos en Brasil se analiza en una perspectiva internacional comparada. Para los más médicos de programa no es más que otra de las estrategias punto entre otras iniciativas gubernamentales del período del informe, al final, se presentan algunos "caminhos" destinadas a promover la sostenibilidad de esta acción y contribuyen a ampliar y cualificar la atención primaria en Brasil.

Palabras clave: Sistema de Salud; Atención Primaria de Salud; Recursos Humanos para la Salud.

\section{INTRODUÇÃO}

A assistência à saúde no Brasil, nas três últimas décadas, tem sido objeto de transformações de natureza variada, sobretudo, a partir da criação do Sistema Único de Saúde (SUS). Apesar dos avanços alcançados nos municípios brasileiros, ainda assim é visto como um sistema em crise, com repercussões negativas nas manchetes de jornais, que exploram a ineficiência, iniquidade, desqualificação profissional, desestruturação dos serviços e a insatisfação da população.

Essa situação tem provocado no sistema educacional, em particular nas instituições de ensino na área da saúde, questionamentos acerca da formação dos recursos humanos, cujo modelo sustentase, principalmente, nas seguintes características: (i) dissociação entre o ensino das ciências biomédicas (anatomia, fisiologia, bioquímica, farmacologia, bacteriologia) nos primeiros anos do curso e as disciplinas de clínica; (ii) pouca ênfase nos aspectos de prevenção e promoção da saúde e concentração nos aspectos da atenção médica individual; (iii) enfoque na doença sem que seja visualizado o sujeito em suas singularidades; (iv) valorização da aprendizagem no ambiente hospitalar, desconhecendo a realidade e o espaço social onde as famílias e comunidades estão inseridas; (v) especialização precoce; (vi) enorme descompasso entre as instituições de ensino superior, os serviços de saúde e as comunidades; (vii) desconsideração do ambiente de trabalho como princípio pedagógico. ${ }^{1}$

Essas características presentes nos cursos da formação médica, mas comum a todos os cursos na área da saúde, têm tido como consequência a formação de profissionais com perfil bastante inadequado à perspectiva de construção de novo modelo de atenção em saúde. Essa inadequação é percebida não só no aspecto técnico, mas, principalmente, na pouca responsabilização social e compromisso ético com os usuários do SUS.

E essa falta de compromisso é expressa na ausência de políticas estruturantes para a formação dos profissionais de saúde no geral e no particular dos médicos. Formação que seja capaz de acompanhar os processos de implementação do SUS e a consequente necessidade de transformação 
das práticas dos profissionais de saúde, que atuam, sobretudo, na rede pública da atenção à saúde. Assim, este ensaio se destina a analisar algumas das razões, motivos políticos e de lacunas da formação médica que levaram o Governo do Brasil a instituir junto aos Ministérios da Saúde e a Educação, o Programa Mais Médicos.

A prática médica especializada, tecnológica e centrada no ambiente hospitalar se reproduz no ideário coletivo tanto dos usuários dos serviços quanto dos atuais e futuros profissionais de saúde. As escolas médicas, preocupadas com a excelência técnica de seus quadros docentes e discentes, reproduzem esse conjunto de ideias e características de um modelo formativo que se arrasta desde a implantação da reforma flexneriana. ${ }^{2}$

Com isso, é "praticamente consensual" no Brasil e no mundo, a incompatibilidade de convivência entre este modelo de prática médica e o acesso universal e equitativo da população aos serviços de saúde. E mais, para superação dessa crise na formação das profissões de saúde, o caminho certo é uma Reforma do Ensino. Reforma que modifique o eixo paradigmático da prática médica, e estimule à formação de profissionais com uma visão holística dos indivíduos, famílias e comunidades.

E, com a entrada do Programa de Saúde da Família (PSF), em 1994, no cenário nacional, este debate fica cada vez mais claro, oportuno, necessário e urgente. Afinal a responsabilidade de cuidar da saúde das famílias de forma universal, integral, equânime, contínua e, acima de tudo, resolutiva, faz do PSF a prioridade central, no âmbito da Atenção Básica capazes de ampliar o debate e as ações estratégicas no desenho e na operacionalização de um novo modelo de atenção à saúde.

E Saúde da Família passa, portanto, a ser um projeto estruturante e provocador de transformações internas no sistema, evidenciado a ruptura, mesmo que gradativa, na dicotomia entre as ações de cunho coletivo e individual, assim como, entre as práticas educacionais e assistenciais.

Aspiração de tamanha envergadura - a reformulação do modelo de atenção à saúde, com profissionais preparados para o exercício de um novo processo de trabalho - põe à vista a necessidade de um diálogo permanente entre os serviços de saúde e as instituições formadoras dos recursos humanos.

\section{Da Política à Formação}

A Constituição Federal ${ }^{3}$, afirma que é de responsabilidade do SUS, a ordenação da formação de recursos humanos. E para se alcançar essa atribuição é necessário tratar a relação saúde e educação como uma questão estratégica. Afinal a qualidade dos serviços socioassistenciais disponibilizados à sociedade depende da estruturação do trabalho, da qualificação e valorização dos profissionais que atuam no setor saúde.

Ceccim, Armani e Rocha ${ }^{4}$ sistematizaram, a partir do marco legal do SUS e dos relatórios das Conferências Nacionais de Saúde, o que foi "pensado, planejado e formulado para a educação de profissionais de saúde no Brasil pelo SUS"7 no período de 1988 a 2002.

Identificaram que as duas Leis Orgânicas reguladoras do SUS ${ }^{5-6}$ mencionam a necessidade 7 p.374. 
de articulação entre as esferas de governo para a formalização e execução da política de recursos humanos, e instituem a exigência de comissão de elaboração de planos de cargos e carreiras como critério para repasse de recursos financeiros do governo federal para estados e municípios.

Esse tema é recorrente nas Conferências Nacionais de Saúde (CNS). Desde a $9^{\text {a }}$ CNS, realizada em 1992, que explicita a indispensável necessidade de formulação e implantação de uma Política Nacional de RH. Uma efetiva política capaz de incorporar as ações dirigidas à formação, capacitação e educação permanente dos profissionais. E que esses processos sejam articulados com as instituições formadoras de recursos humanos, tanto no ensino superior, quanto no médio, sobretudo em uma parceria estreita com Secretarias de Saúde (Estados e Municipios) e Secretarias de Educação. Chamamos atenção aqui para as instituições de ensino profissional, as Escolas Técnicas do SUS (ETSUS), que vem sendo construídas em várias regiões, estados e municípios ao longo de três décadas.

$\mathrm{Na} 10^{\mathrm{a}} \mathrm{CNS}$, há recomendações para que o SUS elabore plano de ordenamento de recursos humanos. Destaca-se ainda "o estímulo à utilização de unidades e serviços de saúde como espaços prioritários para formação de trabalhadores do SUS" além da "interiorização da graduação e da educação continuada". ${ }^{7}$

Realizada em 2000, a $11^{\text {a }}$ CNS discutiu sobre a redução da proteção social e a precarização das relações de trabalho no setor. Para tal, levantou-se a necessidade de formulação de uma política de recursos humanos para o SUS, considerado naquela época um dos maiores problemas das gestões municipais, contemplando uma política de provimento de vagas para ocupação de postos de trabalho, mais especificamente referente à categoria médica, a interiorização, a educação permanente voltada para o acesso, qualidade e humanização, criação de mecanismos de absorção de egressos dos cursos da saúde, entre outros. Era um período de municipalização do sistema e ampliação do acesso aos usuários do SUS das ações e serviços de saúde.

Na $12^{\mathrm{a}}$ realizada, em 2003, $13^{\mathrm{a}}$ em 2007 , e, principalmente, na $14^{\mathrm{a}} \mathrm{CNS}$, realizada em 2011 , seu relatório enfatiza a necessidade da educação permanente, das reformas curriculares, dos planos de carreira e, entre estas várias recomendações no campo da educação e da gestão do trabalho, destaca-se a de: gerar estratégias de fixação de profissionais de saúde no interior do país e em áreas de difícil acesso e provimento, que incluam formação profissional (especialização ou residência) e incentivo salarial e de carreira. ${ }^{8}$

Em todas as conferências mencionadas a questão voltava à tona, entretanto seus principais apontamentos eram colocados em segundo plano, razão pela qual o Conselho Nacional de Saúde organizou a $1^{\text {a }}$ Conferência Nacional de Recursos Humanos (CNRH), realizada em julho de 2009. Essa conferência temática reforçou as críticas ao processo de formação e às consequências desse processo, ou seja, a formação de dos profissionais de saúde não é adequada às necessidades de saúde da população brasileira nem às necessidades dos serviços, e por consequência amplia-se a dificuldade do setor na atração e fixação dos mesmos, sobretudo nas regiões e cidades com perfil socioeconômico e sanitário desiguais do conjunto do país.

Ao longo dos anos 90, na oportunidade das edições das Normas Operacionais Básicas (NOB) 
essa questão era reentrante, a ponto de convergir as ideias da necessidade de desenhar uma Norma especifica para a área de Recursos Humanos para o SUS. Assim, em 1998, foi elaborada, debatida e aprovada no Conselho Nacional de Saúde a NOB-RH SUS. A mesma passou por várias revisões nos anos 2003 e 2005. Nesse último reafirmou os princípios e diretrizes da Política Nacional de Gestão do Trabalho e da Educação em Saúde, no âmbito do SUS. Essa indica como estratégia importante a valorização profissional, regulação das relações de trabalho, e sobretudo, o protagonismo dos trabalhadores da saúde na co-responsabilidade de modificar o modelo de atenção à saúde vigente. Vale lembrar ainda que a decisão de elaborar os "Princípios e Diretrizes para uma Norma Operacional Básica de Recursos Humanos para o SUS" foi tomada entre a Comissão Intersetorial de Recursos Humanos e a Mesa Nacional de Negociação do SUS, baseadas em deliberação da $10^{a}$ Conferência Nacional de Saúde, alterados após a $11^{\text {a }}$ e a $12^{\text {a }}$ Conferências Nacionais de Saúde, pela demonstração da efetividade e unificação normativa dos procedimentos de gestão, no processo de descentralização da gestão do sistema.

Ainda no marco legal com vista à regulação da formação dos RH para o SUS, temos outras referências, a saber: (1) Emenda Constitucional n $n^{0}$ 19/98, artigo 39, que prevê a instituição de um Comitê, no âmbito dos três níveis de governo, para dispor sobre critérios para fixação de padrões de vencimento e obrigatoriedade dos entes federados em manter escolas para formação e aperfeiçoamento do servidor público ${ }^{9}$; e (2) o Decreto 7508/2011 que dispõe sobre a organização do SUS, o planejamento da saúde, a assistência à saúde e a articulação interfederativa, dentre outras. ${ }^{10}$

A Política de Recursos Humanos para o SUS: balanço e perspectivas ${ }^{11}$, deixa claro que o objetivo de uma Política de RH para o SUS pressupõe o desenvolvimento da força de trabalho objetivando a organização do sistema de serviços de saúde, garantindo a universalidade, integralidade, equidade e qualidade das ações de saúde. Com isso, explicita dois pontos essenciais: a formação e a gestão do trabalho. E sem essa integração do mundo do ensino e do trabalho, representados por instituições federais (Ministério da Saúde, Ministério da Educação, Ministério do Trabalho e Emprego, Ministério do Orçamento e Gestão), e gestores estaduais e municipais, por meio das respectivas Secretarias Estaduais e Municipais de Saúde e Conselhos Profissionais, a tarefa fica restrita a ações pontuais e/ou conjunturais. Dito de outra forma, não mexe ainda nas estruturas reguladoras dos processos de ensino e do trabalho. Este fortemente condicionado pelo primeiro e vice-versa.

E ainda, porque ao longo dos 27 anos de implantação do SUS, várias foram às iniciativas para modificação desse quadro, podemos citar entre tantas com maiores ou menores movimentação, envolvimento e articulação do aparelho formador a rede do SUS, com incentivos financeiros e de outras ordens.

No final do ano de 1996 a Coordenação de Saúde da Comunidade (COSAC) da Secretaria de Assistência à Saúde (SAS) do Ministério, atualmente Departamento de Atenção Básica (DAB), da Secretaria de Atenção à Saúde, teve a iniciativa de induzir a implantação de Polos de Capacitação, formação e educação permanente para pessoal do Saúde da Família. Mediante edital $n^{\circ}$ 04, de 06/12/96, foram convocadas as Instituições de ensino e serviço a apresentarem projetos que possibilitassem uma ação renovada no espaço de articulação ensino-serviço, para a capacitação e 
formação de profissionais capazes de construir o PSF nas diferentes regiões do país.

Esses tinham como tarefa central articular e abrir o diálogo social em torno de uma agenda concreta, capaz de ampliar o debate da mudança na formação dos profissionais da saúde, e com isso, traziam para a mesa nacional a rediscussão dessa problemática e a possibilidade de encontrar caminhos para seu enfrentamento.

Foram apresentados 21 projetos que, ao serem analisados, resultaram em aprovação de dez como polos, seis como projetos de capacitação e cinco como projetos de cursos instalados. Os projetos que não se caracterizaram como polos e sim como centros de capacitação e cursos introdutórios e desempenharam um importante papel na preparação de recursos humanos para o PSF, cuja agenda foi construída a curto, médio e longo prazo, considerando os seguintes compromissos: (i) oferta de cursos de atualização para os membros das ESF; (ii) acompanhamento e avaliação do trabalho das equipes nas UBSF; (iii) implantação de programas de educação permanente destinados às ESF; e (iv) implantação de cursos de especialização ou outras formas de cursos de pós-graduação lato sensu, iniciativa esta destinada a introduzir inovações curriculares nos cursos de graduação.

A complexidade desses compromissos sinalizava para a necessidade de ampliação da rede de instituições parceiras envolvidas com os Pólos. Para tanto, em 1998, a Secretaria de Assistência à Saúde (SAS/MS) lançou um novo edital, estimulando que cada Unidade da Federação tomasse para si a responsabilidade de fortalecer a rede Polo no Estado e no conjunto de suas regiões e municípios. ${ }^{12}$

O Programa de Interiorização do Trabalho em Saúde (PITS) ${ }^{13}$, estratégia para reforçar a fixação dos profissionais do Programa Saúde da Família (PSF), sobretudo os médicos, que em várias pesquisas apontavam a alta rotatividade desses trabalhadores, foi responsável pela ampliação do acesso e da cobertura assistencial de várias localidades carentes de atendimento à saúde.

Mais recentemente, por força do Plano Nacional de Saúde (PNS) foi criado um conjunto de medidas educacionais, regulatórias e, no âmbito da gestão do trabalho, necessárias para o sistema entre elas o Programa de Valorização da Atenção Básica (PROVAB), que objetiva prover e incentivar profissionais a atuarem na atenção básica, através de estratégias de educação à distância e supervisão pedagógica articulada ao bônus de $10 \%$ nas provas de residência médica para aqueles que tiverem interesse em ingressar nos programas de residência.

Segundo Carvalho e Sousa ${ }^{14}$ :

"Em termos de abrangência, diferentemente do Projeto Rondon e do PITS, o PROVAB 2012 permitiu com que os 5.565 municípios brasileiros pudessem concorrer a uma vaga, manifestando a sua adesão de acordo com cinco perfis articulam critérios como capital e região metropolitana, municípios beneficiados pelo FIES, população rural com extrema pobreza". ${ }^{8}$

Também se destaca o Fundo de Financiamento ao Estudante do Ensino (FIES), criado pela Medida Provisória n ${ }^{\circ}$ 1.827, de 27/05/99 e regulamentado pelas Portarias MEC nº 860, de 27/05/99

8 p. 917.

Tempus, actas de saúde colet, Brasília, 9(4), 159-174, dez, 2015.

ISSN 1982-8829 
e 1.386/99, de 15/19/99 e Resolução do Conselho Monetário Nacional 2647, de 22/09/99. Em 2010, através da Lei $n^{\circ} 12.202 / 2010$, o governo possibilitou estender os benefícios do programa para os médicos que atuam na Atenção Básica em regiões prioritárias para o SUS, concedendo assim abatimento de $1 \%$ do saldo de dívidas com direito à carência estendida.

Até então as iniciativas focavam na educação permanente. A partir do Programa Nacional de Incentivo a Mudanças Curriculares nos Cursos de Medicina (PROMED), em 2002, desenhado pelos Ministérios da Saúde, da Educação e a OPAS, além da parceria com a Associação Brasileira de Educação Médica (Abem) e a Rede Unida, inicia o investimento federal para induzir mudanças nos cursos de graduação da medicina. Após contemplar 19 escolas médicas no Brasil, em 2005, amplia este investimento, também, para os cursos de enfermagem e odontologia com a publicação do edital do Programa Nacional de Reorientação da Formação Profissional em Saúde (Pró-Saúde) 15. Esse tem por objetivo central incentivar transformações do processo de formação, geração de conhecimentos e prestação de serviços à população, para abordagem integral do processo de saúdedoença.

Para tanto, foram desenhados quatro objetivos específicos: (1) reorientar o processo de formação em medicina, enfermagem e odontologia, de modo a oferecer à sociedade, profissionais habilitados para responderem às necessidades da população brasileira e à operacionalização do SUS; (2) estabelecer mecanismos de cooperação entre os gestores do SUS e as escolas de medicina, enfermagem e odontologia, visando tanto à melhoria da qualidade e à resolubilidade da atenção prestada ao cidadão quanto à integração da rede pública de serviços de saúde e à formação dos profissionais de saúde na graduação e na educação permanente; (3) incorporar, no processo de formação da medicina, enfermagem e odontologia, a abordagem integral do processo saúde-doença e da promoção de saúde; e (4) ampliar a duração da prática educacional na rede pública de serviços básicos de saúde. Neste ano de 2015 o Pró Saúde completa uma década a partir do lançamento da primeira de suas três edições ${ }^{16}$ e incluiu os cursos das 14 profissões da saúde.

Vale mencionar também o Programa de Educação pelo Trabalho para a Saúde (PET-Saúde), criado pela Portaria Interministerial MS/MEC n ${ }^{0} 1.802$, de 26 de agosto de 2008. O PET-Saúde tem como fio condutor a integração ensino-serviço-comunidade, uma parceria entre a Secretaria de Gestão do Trabalho e da Educação na Saúde (SGTES) e SAS/MS, e a Secretaria de Educação Superior (SESU), do Ministério da Educação. Além do Programa de Qualificação e Estruturação da Gestão do Trabalho e da Educação no SUS (ProgeSUS), criado com o objetivo de propor diretrizes organizacionais e oferecer ferramentas, suporte e mecanismos para a organização, modernização e profissionalização da gestão do trabalho e da educação nas Secretarias Estaduais e Municipais de Saúde. ${ }^{17-18}$

E em 18 de junho de 2008, se deu a criação da Universidade Aberta do Sistema Único de Saúde (UNASUS). Um programa que gera condições para o funcionamento de uma rede colaborativa de instituições acadêmicas, serviços de saúde e gestão do SUS, destinada a atender as necessidades de formação e educação permanente do SUS, com destaque para oferta de cursos de especialização em Saúde da Família. Além de (1) criar um acervo público e colaborativo de materiais educacionais para área da saúde; (2) promover a incorporação de novas tecnologias de informação e comunicação 
aos processos de educação em saúde; (3) oferecer apoio presencial aos processos de aprendizagem em saúde, e (4) disponibilizar aos trabalhadores da saúde a oferta de cursos adequados à realidade local, utilizando-se de interações presenciais e a distância, com vistas à capacitação em áreas estratégicas para o SUS.

Em novembro de 2013, sob a coordenação da Organização Mundial da Saúde (OMS), em parceria com a Organização Pan-Americana da Saúde (OPAS) e com o Ministério da Saúde, realizou-se o III Fórum Global sobre Recursos Humanos em Saúde, no Brasil, a fim de discutir a agenda global em recursos humanos em saúde. A conferência culminou na Declaração de Recife ${ }^{19}$, declaração política de compromisso dos países membros, que incluem itens como: um plano sustentável de financiamento; a integração dos processos de formação de profissionais da saúde apoiado por novas tecnologias de informação e comunicação; o enfoque especial na atenção básica; a governança transparente e responsável em todo o processo de expansão da força de trabalho em saúde, considerando também o desenvolvimento de planos de carreiras; a adequada distribuição e retenção dos profissionais de saúde nas áreas desfavorecidas e o desenvolvimento de pesquisa e estratégias inovadoras.

As iniciativas governamentais mencionadas, em tese, foram apresentadas e discutidas na Mesa Nacional de Negociação do SUS todas como estratégias para enfrentamento dos problemas referentes à formação, distribuição, provimento e fixação de profissionais de saúde e carreira.

O que podemos ver ao longo das últimas três décadas, ainda que reconhecendo avanços pontuais, os esforços de integração do processo de ensino com a rede de serviços tiveram baixa sustentabilidade, na medida em que dependeram de uma adesão idealista de docentes e estudantes a essa iniciativa e, mesmo estando institucionalizadas, mostraram-se vulneráveis às conjunturas políticas locais. Assim, os deslocamentos para ambulatórios periféricos, a supervisão de internatos rurais, a participação em atividades comunitárias, entre outras, não se reverteram em incentivos, quer para progressão na carreira, reconhecimento acadêmico ou ganho financeiro, para aqueles que as assumiam e as levavam adiante.

Por essas e outras razões as questões referentes ao ensino e trabalho na saúde, seguem governos a governos, da direita à centro esquerda, com propostas, ainda que meritosas, frágeis na base do problema. Ou seja, seguem tendo pouco ou quase nada de pacto federativo. Onde ocorra uma real participação das Instituições de Ensino Superior (IES) e demais órgãos dos governos federal, estaduais e municipais. Com a passividade do Congresso Nacional, bem como das representações de entidades corporativas, a exemplo da Associação Brasileira de Educação Médica (ABEM), Associação Brasileira de Enfermagem (ABEn), Conselho Federal de Medicina (CFM), Associação Médica Brasileira (AMB), Sociedades de Especialistas, de forma a construir uma agenda estruturante que sirva de base operadora de efetiva Política Nacional de Recursos Humanos para o SUS. Nessa esteira o Brasil lança o "Programa Mais Médicos", por quê?

\section{Fatos fundantes à criação do Mais Médicos}

Na última edição da Demografia Médica, o Brasil possui 432.870 mil médicos ativos e apresenta uma proporção de 2,1 médicos para cada 1.000 (mil) habitantes. A proporção de médico/1.000 
habitantes constatada é menor ainda em outros países, a exemplo da Coreia do Sul, Turquia, Chile, China, África do Sul, Índia e Indonésia, também abaixo do Brasil. Afirma ainda a pesquisa que apenas a Grécia, com 6,1 profissionais por 1.000 habitantes, possui as melhores proporções, “seguido pela Rússia, com 5; Áustria, 4,8; Itália, com 4,1; Portugal, 4,0; Suécia, 3,9; e Alemanha, $\operatorname{com} 3,8 " .20$

Não existe parâmetro que estabeleça uma proporção ideal de médico por habitante reconhecido e validado internacionalmente. Para tanto, utiliza-se como referência a proporção de 2,8 médicos por 1.000 habitantes, que é a encontrada no Reino Unido ${ }^{20}$, país que, depois do Brasil, tem o maior sistema de saúde público de caráter universal orientado pela atenção básica.

Quanto aos Estados que apresentam um quantitativo de médicos acima da média nacional, os casos do Distrito Federal, São Paulo, Rio de Janeiro e Minas Gerais, exibem internamente consideráveis diferenças em suas regiões e municípios. ${ }^{20}$

Muitas são as manifestações no tocante ao diagnóstico da necessidade de médicos no Sistema Único de Saúde, em especial na rede básica de saúde, que desde 1994 vem sendo reestruturada por meio da Estratégia de Saúde da Família. E ainda que, reconhecendo seus resultados ao longo de duas décadas, várias são as regiões, estados e municípios com territórios vazios no tocante à assistência médica.

Para Dal Poz 21 “A má-distribuição caracterizada pela concentração urbana e deficits rurais não é privilégio de nenhum país em particular, pois quase todos os países sofrem esses desequilíbrios"9. É historicamente reconhecida a concentração desses profissionais em grandes centros urbanos e em regiões mais desenvolvidas do país, o que acarreta nas demais regiões a baixa capacidade em prover e fixar profissionais de saúde na atenção básica, em especial os médicos, comprometendo a ampliação do acesso, com qualidade aos serviços básicos de saúde.

Várias são as pesquisas que apontam essa questão entre elas podemos citar a realizada pelo Instituto de Pesquisa Econômica Aplicada (IPEA), em 2011, com 2.773 entrevistados, que revelou que $58,1 \%$ da população apontou a falta de médicos como o principal problema do SUS ${ }^{22}$. Antes dessa faz-se necessário recordar mais três outras: O Perfil dos Médicos e Enfermeiros do PSF, coordenada pelo Núcleo de Pesquisas em Recursos Humanos em Saúde (NERHUS), da Escola de Saúde Pública (ENSP) da Fiocruz; a pesquisa Avaliação dos Polos de Capacitação, pelo Núcleo de Estudos de Políticas Públicas da UNICAMP (NEPP); e a Pesquisa de Monitoramento das Equipes de Saúde da Família, esta realizada pela Coordenação de Avaliação e Acompanhamento do Departamento de Atenção Básica. ${ }^{23}$

Em todas as pesquisas alguns aspectos são convergentes: (i) a alta rotatividade dos profissionais entre os municípios; (ii) a falta de condições para o trabalho (iii) a precarização do vínculo trabalhista, com contratos temporários; (iv) a necessidade de revisão da formação, sem perfil adequado para a responsabilidade a eles atribuídas, sobretudo nas ações de cunho preventivo e de promoção à saúde; e (v) o descumprimento da carga horária de 40 horas de trabalho, entre outros.

9 p. 1924. 
Os resultados destas pesquisas deveriam ter sido utilizados para subsidiar as negociações e definições de ações estratégicas no que diz respeito à formação, capacitação e educação permanente para o pessoal envolvido no SUS em geral e no particular da Atenção Básica/ Estratégia Saúde da Família.

Outros movimentos emergiram no cenário nacional diante dos problemas enfrentados pela população brasileira em função da falta de médicos na rede pública de saúde, a exemplo da Frente Nacional de Prefeitos, que em março de 2013, lançou a campanha "Cadê o médico". E, principalmente pelo tensionamento ocorrido em junho em todo o país pelos movimentos de rua. Foram movimentos massivos que se diferenciam radicalmente dos "movimentos sociais" sob o controle do Estado, dos partidos políticos entre eles dos Trabalhadores (PT) e organizações sociais como o MST, por exemplo. O fato é que em suas reivindicações de ordem genérica a agenda da saúde era posta como tema central, entre as agendas de educação, transporte e segurança pública.

Isso fez com que os Ministérios da Saúde, Educação e Planejamento, Orçamento e Gestão enviassem a Presidência da República uma exposição de motivos para o Projeto de Medida Provisória que instituiu o Programa Mais Médicos, ${ }^{24-25} \mathrm{com}$ a finalidade de: (I) diminuir a carência de médicos nas regiões prioritárias para o SUS, a fim de reduzir as desigualdades regionais na área da saúde; (II) fortalecer a prestação de serviços na atenção básica em saúde no país; (III) aprimorar a formação médica no país e proporcionar maior experiência no campo de prática médica durante o processo de formação; (IV) ampliar a inserção do médico em formação nas unidades de atendimento do SUS, desenvolvendo seu conhecimento sobre a realidade da saúde da população brasileira; (V) fortalecer a política de educação permanente com a integração ensinoserviço, por meio da atuação das instituições de educação superior na supervisão acadêmica das atividades desenvolvidas pelos médicos; (VI) promover a troca de conhecimentos e experiências entre profissionais da saúde brasileiros e médicos formados em instituições estrangeiras; (VII) aperfeiçoar médicos nas políticas públicas de saúde do país e na organização e funcionamento do SUS; e (VIII) estimular a realização de pesquisas aplicadas no SUS.

Os itens que compunham o discurso oficial para justificar a criação do Programa Mais Médicos, por parte dos Ministérios da Saúde, Educação e Planejamento, Orçamento e Gestão foram: Primeiro - o número insuficiente de vagas nos cursos de graduação em Medicina. Apesar de um número absoluto de escolas médicas maiores do que alguns países (são 257 escolas médicas), ao analisarse a proporção de vagas de ingresso para cada 10.000 (dez mil) habitantes, o país apresenta índice significativamente inferior.

Segundo - poucas vagas para novos médicos oferecidos pelas escolas. Terceiro - a escassez de médicos em diversas regiões, presente em análises realizadas sobre o mercado de trabalho, como no estudo Demografia do Trabalho Médico, do Núcleo de Educação em Saúde Coletiva da Universidade Federal de Minas Gerais (UFMG), baseado em dados da Relação Anual de Informações Sociais (RAIS).

Diante desses e outros fatos, o Congresso Nacional aprovou a Lei $12.871^{26}$, que institui o Programa Mais Médicos, com a finalidade de formar recursos humanos na área médica para o SUS, 
além de acelerar os investimentos em infraestrutura na área. $\mathrm{O}$ mesmo constitui-se de três eixos: (1) criação de novas vagas de graduação em medicina, bem como mudança na lógica de abertura dos cursos para atender as áreas prioritárias do SUS; (2) aprimorar a formação médica, incluindo nela a experiência do formando no SUS; e (3) garantir a assistência médica nas periferias de grandes cidades e municípios de interior, priorizando municípios em região metropolitana, capital, municípios que fazem parte do chamado G100 (municípios populosos, com baixa receita per capita e alta vulnerabilidade socioeconômica) e municípios que têm $20 \%$ ou mais de sua população em situação de extrema pobreza.

Além destes municípios, foram priorizadas populações de maior grau de vulnerabilidade social e sanitária como os quilombolas ${ }^{27}$ e povos indígenas para contratação dos médicos participantes do Programa.

Desde o anúncio do Programa Mais Médicos, vários foram os debates por diferentes sujeitos sociais e matizes ideológicas, entretanto o confronto mais acirrado se deu entre o representante do governo, e sua base de sustentação no Congresso Nacional e as corporações médicas, sobretudo o Conselho Federal de Medicina.

A mídia lançou mão desse debate ampliando as teses favoráveis e desfavoráveis no entorno do Programa. O que provocou uma série de pesquisas de opinião pública entre elas a do CNI Ibope, realizada em julho de 2013. A mesma revelou que a população entende que a responsabilidade da Saúde é dividida entre os governos federal, estadual e municipal. ${ }^{26}$

Em agosto de 2013, foi realizada também uma pesquisa pelo Datafolha, que mostrou que 54\% da população entrevistada aprovaram o Programa Mais Médicos, sendo que a região Nordeste concentrou o maior percentual de aprovação. ${ }^{25} \mathrm{O}$ Programa prevê ainda a inserção de profissionais médicos formados no exterior, caso ocorra o não preenchimento das vagas por médicos brasileiros.

\section{Mais médicos para o Brasil, por quê?}

Destaca-se que, de acordo com a criação do Programa Mais Médicos ${ }^{26-28}$, o Ministério da Saúde passa a ser responsável pela emissão dos registros dos estrangeiros, ainda que a fiscalização siga sendo realizada pelos Conselhos Regionais de Medicina. Após os três primeiros anos de participação no programa, o médico estrangeiro deverá fazer o exame de revalidação de diploma, o Revalida. 30\% da carga horária do internato na graduação deverão ser efetuadas nas Redes Básica e de Urgência e Emergência no âmbito do SUS. E mais, os graduados em Medicina terão de fazer de um a dois anos de residência em Medicina Geral de Família e Comunidade para ingressar nas demais especializações.

Os médicos de instituições de educação superior brasileiras ou com diploma revalidado que participarem integralmente das atividades do Programa Mais Médicos por pelo menos um ano, receberão pontuação adicional de $10 \%$ na nota de todas as fases ou da fase única do processo de seleção pública dos Programas de Residência Médica.

No tocante à adesão ao Programa, 4.025 municípios aderidos demandaram 16.631 médicos 
1.878 adesões de municípios prioritários; 2.147 nas demais localidades. ${ }^{29}$ O Ministério da Saúde, através da Secretaria de Gestão do Trabalho e da Educação na Saúde (SEGTS), atendeu em parte as demandas dos municípios.

No primeiro ciclo do Programa, apesar de uma demanda significativa dos municípios por esses profissionais, somente 381 médicos foram vinculados. Na segunda edição do programa, aderiram 2.838 municípios que solicitaram 13.862 médicos para atuar na atenção básica, sendo que apenas 3.577 médicos foram vinculados ao Programa para atuação em 1.260 municípios. Ainda assim, mesmo com esse aumento de um ciclo para outro na participação de médicos, permanece um número significativo de vagas ociosas, correspondendo a $74,2 \%$ da demanda inicial. ${ }^{30}$

Nesse sentido, o Programa Mais Médicos para o Brasil selecionou médicos para participarem dessa iniciativa, garantindo a seleção de médicos formados em instituições de educação superior nacionais ou com diploma revalidado. Diante das vagas não preenchidas pelos profissionais brasileiros, foram ofertadas as instituições estrangeiras com habilitação para exercício da Medicina no exterior e, em seguida, a médicos estrangeiros com habilitação para exercício de Medicina no exterior, mediante chamada pública internacional ou celebração de instrumentos de cooperação com organismos internacionais. No caso de Cuba, foi celebrado um termo de parceria junto a Organização Pan-Americana de Saúde (OPAS), representação Brasil, como mediadora da relação Brasil-Cuba.

Por fim, fica a pergunta Mais Médicos para o Brasil, por quê? Se esta iniciativa se configura, mais uma vez em uma ação pontual, de um governo pressionado pelos reclames dos movimentos de rua, da mídia, da população que de fato sofre sem cuidados do profissional médico. "Será que mais uma experiência desse porte contribuirá para mudar o paradigma atual da formação desses profissionais, sob o ponto de vista teórico-metodológico, onde a educação médica passe a considerar a formação de especialista em gente", nos dizeres do professor Adib Jatene? Ou seja, as Instituições de Ensino Superior, sobretudo as públicas, assumiram o compromisso e responsabilidades com uma formação dos médicos preocupados com o ser humano na sua globalidade, alteridade e condição de sujeito da sua própria história, rompendo com as estruturas conservadoras, autoritárias e mercadológicas da formação vigente?

Cyrino et al ${ }^{31}$ ressaltam o papel indutor do Programa na revisão das DCN dos cursos de medicina e citam que "foram autorizadas 4.460 novas vagas de graduação, em instituições públicas e privadas, além da seleção de 39 municípios para criação de novos cursos" ${ }^{10}$. É preciso indagar se esta expansão está se concentrando nas escolas privadas e/ou se as matrizes curriculares aprovadas garantem a reforma estruturante que propõem as novas diretrizes. A defesa da expansão das vagas nas instituições públicas visa aperfeiçoar, revitalizar a estrutura já existente e favorecer a superação das iniquidades regionais no acesso ao ensino superior.

E os sistemas e serviços de saúde, cujas atribuições são compartilhadas entre os três gestores do SUS (Federal, Estaduais e Municipais) aprenderam o que com essa convivência? Passado o tempo dos médicos nos municípios brasileiros, sobretudo os estrangeiros, as Redes de Atenção

10 p. 5 .

Tempus, actas de saúde colet, Brasília, 9(4), 159-174, dez, 2015.

ISSN 1982-8829 
à Saúde ficarão ordenadas pela Atenção Básica à Saúde? Esta caracterizada por um conjunto de ações de saúde, nos âmbitos individual e coletivo, abrangendo a promoção e a proteção da saúde, a prevenção de agravos, o diagnóstico, o tratamento, a reabilitação, redução de danos e a manutenção da saúde com o objetivo de desenvolver uma atenção integral que impacte na situação de saúde das coletividades? E mais, suas ações estarão orientadas pelos princípios da universalidade, da acessibilidade, do vínculo, da continuidade do cuidado, da integralidade da atenção, da responsabilização, da humanização, da equidade e da participação social?

Os gestores do SUS seguiram perseguindo as metas, expressas nos discursos oficiais de governos de expandir e a qualificação da atenção básica. Esta seria reorganizada pela Estratégia de Saúde da Família? Com isso ficaria resolvido, por meio de uma política tripartite, a situação do provimento e fixação dos profissionais de saúde na atenção básica, no particular e no geral no SUS, resolvendo de forma estruturante o acesso às ações e serviços de saúde, o mais próximos possível das famílias em seus territórios de trabalho, moradia e vida?

E para não descuidar do tempo político, e de uma antevisão, é necessário, urgente e ético, apontar os caminhos, entre outras direções para: (i) estruturar uma carreira de estado, com salários dignos, progressão e prestígio profissional para todos os profissionais de saúde, porque esta não se faz apenas com o médico, muito embora seja importante em processos de trabalho multiprofissional; (ii) instituir um serviço civil solidário com prioridade para os territórios de maior exclusão social; (iii) redefinir os mecanismos de financiamento para bolsas de residências em medicina de família e comunidade; (iv) estruturar redes de apoio político, técnico e científico inter-regionais, interestaduais e intermunicipais, para fortalecer as "jovens" escolas de formação na saúde, apoiando-as em suas redefinições dos modelos teórico-metodológicos, sobretudo, elaborando mecanismos de incentivo financeiro àquelas que redirecionem seus currículos para formação dos profissionais adequados à atenção básica/Saúde da Família, prioritariamente; (v) articular outros sujeitos sociais, dentro e fora do setor saúde, para formular políticas integradoras, diminuindo as desigualdades sociais e na saúde, sem perder o horizonte da universalização desses serviços.

A OMS ${ }^{32}$ destaca entre as suas recomendações globais para a retenção dos trabalhadores da saúde que "a colaboração intersetorial é chave nesta área, pois requer na prática intervenções dos setores do trabalho, finanças/planejamento, desenvolvimento local” e, não somente da educação.

Em síntese, podemos seguir nos instigando no entendimento do por que Mais Médicos para o Brasil. Se o modelo de sua formação recai sobre uma série de contradições aos elementos que constituem os ideários da política. E mais, corremos o risco de reforçar o modelo centrado do tripé da biomedicina, do complexo médico industrial e no saber da ciência médica, que diminuem a força impulsionadora, nos diversos municípios brasileiros, de um novo modelo de atenção à saúde, cujos eixos estruturantes sejam a composição de equipes multiprofissionais, a interdisciplinaridade, o compromisso ético familiar e comunitário, onde o símbolo maior seja a defesa incessante da saúde coletiva e da vida, quiçá da felicidade.

\section{REFERÊNCIAS BIBLIOGRÁFICAS}

1. Morais I.; Alkmin D.: Lopes J.; et al. Jornais Folha de São Paulo e Correio Braziliense: o 
que dizem sobre o Programa Mais Médicos?. Rev. esc. enferm. USP [Internet]. 2014; 48(spe2): 107-115. Disponível em <http://www.scielo.br/scielo.php?script=sci_arttext\&pid=S0080$62342014000800107 \& \operatorname{lng}=$ en $>$. Acesso em dez 2015.

2. Sousa MF. (org). Os sinais vermelhos do PSF. São Paulo: Hucitec, 2002.

3. Brasil. Constituição da República Federativa do Brasil. Brasília, DF: Senado, 1998.

4. Ceccim RB.; Armani TB; Rocha CF. O que dizem a legislação e o controle social em saúde sobre a formação de recursos humanos e o papel dos gestores públicos, no Brasil. Ciência \& Saúde Coletiva 2002; 7(2):373-383.

5.

Lei no 8.080, de 19 de setembro de 1990. Dispõe sobre as condições para a promoção, proteção e recuperação da saúde, a organização e o funcionamento dos serviços correspondentes e dá outras providências. Disponível em $<$ http://www.planalto.gov.br/ccivil_03/ leis/L8080.htm> Acesso em dez 2015.

6. Lei $\mathbf{n}^{\circ} \mathbf{8 . 1 4 2}$, de 28 de dezembro de 1990. Dispõe sobre a participação da comunidade na gestão do Sistema Único de Saúde (SUS) e sobre as transferências intergovernamentais de recursos financeiros na área da saúde e dá outras providências. Disponível em < http://www.planalto.gov.br/ccivil_03/leis/L8080.htm> Acesso em dez 2015.

7. Brasil. Relatório Final da $\mathbf{1 0}^{\text {a }}$ Conferência Nacional de Saúde. Brasília: Ministério da Saúde.1996. Disponível em <http://bvsms.saude.gov.br/bvs/publicacoes/10conferencia.pdf > Acesso em dez 2015.

8.

Relatório Final da 14a Conferência Nacional de Saúde. Brasília: Ministério da Saúde. 2012. Disponível em <http://conselho.saude.gov.br/14cns/docs/Relatorio_final.pdf $>$ Acesso em dez 2015.

9. . Emenda Constitucional nº 19/98, artigo 39. Brasília, DF: Senado, 1998.

Disponível em < http://www.planalto.gov.br/ccivil_03/Constituicao/Emendas/Emc/emc19. htm $>$ Acesso em dez 2015.

10. . Decreto 7508, de 28 de junho de 2011. Regulamenta a Lei 8080, de 19

de setembro de 1990, e dá outras providências. Disponível em <http://www.saude.mg.gov.br/ atos_normativos/legislacao-sanitaria/dec-7508-2011-

reg-8080-29-6-2011.pdf> Acesso em dez 2015.

11. . Ministério da Saúde. Secretaria de Políticas de Saúde. Coordenação-Geral da Política de Recursos Humanos. Política de Recursos Humanos para o SUS: balanço e perspectivas. Brasília: Ministério da Saúde, 2003. Disponível em: < http://bvsms.saude.gov.br/ bvs/publicacoes/cd03_16.pdf>. Acesso em dez 2015. 
12. Sousa MF. Programa Saúde da Família no Brasil. Análise da desigualdade no acesso à atenção básica. Brasília: Editora do Departamento de Ciências da Informação e Documentação da Universidade de Brasília, v.1, 2007.

13. Brasil. Ministério da Saúde. Secretaria de Gestão do Trabalho e da Educação na Saúde, Secretaria de Atenção à Saúde, Departamento de Atenção Básica. InformAção - Programa de Interiorização do Trabalho em Saúde/PITS. Brasília: Ministério da Saúde. 2003.

14. Carvalho MS; Sousa MF. Como o Brasil tem enfrentado o tema provimento de médicos?. Interface (Botucatu) [Internet]. 2013, 17(47):913-926.

15. Dias HS, Lima LD, Teixeira, M. A trajetória da política nacional de reorientação da formação profissional em saúde no SUS. Ciência \& Saúde Coletiva, 2013; 18(6):1613-1624.

16. Rocha DG; Sousa E.; Marcelo VC; Lima, AA. Editorial Reorientação da formação na graduação em saúde e efetividade da parcela universidade serviço comunidade. Tempus, actas de saúde colet 2015; 9 (1): 7-9.

17. Brasil. Ministério da Saúde. Ministério da Educação. Portaria Interministerial no 1.802, de 26 de agosto de 2008. Institui o Programa de Educação pelo Trabalho para a Saúde- PET - Saúde. Brasília; 2008. Disponível em <http://bvsms.saude.gov.br/bvs/saudelegis/gm/2008/ pri1802_26_08_2008.html> Acesso em dez 2015.

18. Ministério da Saúde. Secretaria de Gestão do Trabalho e da Educação na Saúde, Departamento de Gestão e da Regulação do Trabalho em Saúde. Programa de qualificação e estruturação da gestão do trabalho e da educação no SUS - ProgeSUS. Brasília: Ministério da Saúde, 2006.

19. OMS. Declaração de Recife. III Fórum Global de Recursos Humanos em Saúde. Organização Mundial da Saúde; Brasil: Ministério da Saúde, 2013. Disponível em: < http://www. who.int/workforcealliance/forum/2013/recife_declaration_13nov.pdf?ua=1> Acesso em dez 2015.

20. Dal Poz MR. A crise da força de trabalho em saúde. Cad. Saúde Pública [online]. 2013, vol.29, n.10, p. 1924-1926.

21. Cremesp. Demografia Médica no Brasil 2015. Scheffer M. (coord.) São Paulo:

Departamento de Medicina Preventiva da Faculdade de Medicina da USP; Conselho Regional de Medicina do Estado de São Paulo; Conselho Federal de Medicina, 2015.

22. Ipea. Sistema de Indicadores de Percepção Social (SIPS). Brasília: Instituto de Pesquisa Econômica Aplicada, 2011. Disponível em: <http://www.ipea.gov.br/portal/images/stories/PDFs/ SIPS/110207_sipssaude.pdf $>$ Acesso em dez 2015.

23. Sousa MF; Hamann EM. Programa Saúde da Família no Brasil: uma agenda incompleta? Ciênc. saúde coletiva [online]. 2009, vol.14, suppl.1, p. 1325-1335.

24. Ibope. Pesquisa CNI - IBOPE: avaliação do governo - (nov 2013). Brasília: CNI, 2013. 
Disponível em < http://arquivos.portaldaindustria.com.br/app/conteudo_18/2013/12/13/5702/2 0131213174241896838 e.pdf $>$. Acesso em dez 2015.

15. Datafolha. Pesquisa de opinião sobre projeto dos médicos estrangeiros. Ago 2013. Disponível em $<$ http://media.folha.uol.com.br/datafolha/2013/08/12/opiniao-projeto-medicosestrangeiros.pdf $>$ Acesso em dez 2015.

26. Brasil. Lei 12.871 de 22 de outubro de 2013. Institui o Programa Mais Médicos, altera as Leis no 8.745, de 9 de dezembro de 1993, e no 6.932, de 7 de julho de 1981, e dá outras providências. 2015.

27. Pereira LL; Silva HP; Santos LMP. Projeto Mais Médicos para o Brasil: estudo de caso em comunidades quilombolas. Revista da ABPN 2015; v. 7, n. 16, mar - jun. p.28-51.

28. . Ministério da Saúde. Programa Mais Médicos. 2013. Disponível em $<$ http:// www.saude.gov.br/maismedicos>. Acesso em dez 2015.

29. . Medida Provisória no 621, de 8 de Julho de 2013. Disponível em <http://bvsms. saude.gov.br/bvs/saudelegis/gm/2013/pri1369_08_07_2013.html> Acesso em dez 2015.

30. Sistema de Gerenciamento de Programas da Secretaria de Gestão do Trabalho e da Educação na Saúde. Ministério da Saúde. Brasília. Disponível em <http://maismedicos. saude.gov.br/loginExt.php> Acesso em dez 2015.

31. Cyrino EG; Pinto EH; Oliveira FP; Figueiredo, AM. O Programa Mais Médicos e a formação no e para o SUS: por que a mudança? Esc Anna Nery 2015;19(1):05-06.

32. World Health Organization. WHO global recommendations for the retention of health workers. Disponível em http://www.who.int/hrh/migration/retention/en/ Acesso em dez 2015.

Artigo apresentado em 22-09-15 Artigo aprovado em 28-11-15 Artigo publicado no sistema em 30-12-15 